\title{
Comparative Analysis of Cost and Benefits of Training
}

\author{
Manzoor Ali ${ }^{1}$, Aftab Ahmed ${ }^{2}$, Musarrat Karamat ${ }^{3}$, Nadir $\mathrm{Ali}^{4}$ \\ ${ }^{1,3}$ Department of Management Sciences, BUITEMS, Quetta \\ Email: manzoor.ali@buitms.edu.pk, musarrat.ali@buitms.edu.pk \\ ${ }^{2}$ Department of Computer Science, BUITEMS, Quetta \\ Email: aftab.ahmed@buitms.edu.pk \\ ${ }^{4}$ Department of Petroleum \& Gas, BUITEMS, Quetta \\ Email: nadir.khoso@ buitms.edu.pk
}

\begin{abstract}
The study is focused on comparative analysis of cost and benefit of training whether training increases efficiency or cost. The view often favors that training increases efficiency but it may also cause for huge cost to incur. Managers are interested to know the Return on Invest (ROI) in order to evaluate the training sessions effectively. Training cost includes cost of training design, trainer's fees, personnel cost, hardware resources cost, etc. Training benefits includes effective transfer of training, enhancement of skills of trainees, improved work performance, reliable and accurate transaction handling etc. For the purpose, the research is conducted in banks at Karachi, Pakistan to find out the outcomes which may be helpful in decision making. As banks have gone through major training sessions and shifted from manual work to computerized transactions, therefore, it becomes important to find out the cost as well as benefits of training. In preliminary research, it has been found that some managers are of view that training always increases efficiency while some managers consider it as total wastage of resources. Dual opinion about the subject has emphasized to conduct empirical research to find out the outcomes.
\end{abstract}

Keywords: Benefits, Comparative Analysis, Cost, Efficiency, Training.

\section{Introduction}

\subsection{Background Study}


Training is very important practice of Human Resource Management which leads towards improvement of workers' performance and avoids wastages. Organizations mostly arrange training programs in order to make familiar their employees about latest changes in technology and other factors which are related to job performance. However, cost is also necessary to determine to compare it with the benefits extracted from training.

The most important thing here to discuss is Transfer of Training which includes a responsible effort to transfer knowledge, skills and competency from trainer to trainees. The banks have shifted their working procedure from manual to computerized, introduced new product lines, improved their working conditions with latest tools and technologies for better service to their customers. These improvements may provide source of sustainability to banks and other firms in competitive environment. Such changes are actually driving forces for organization to be ready for training and development practices.

\subsection{Problem Statement}

Managers are mostly unknown to the outcomes of training as majority of organizations do not go through proper measurement of effectiveness of training. The training may increase the cost which ultimately reduces the profitability of organizations. Some organization believe that training increases efficiency therefore, they do not go comparative analysis of training in order to measure the positive as well as negative outcomes of the training.

\subsection{Research Objectives}

The objective of study is to find out the result of training in banks and direct managers to put strategies accordingly. However, researcher will also include the opinion from middle and low level managers regarding contribution of training in improvement of their work in order to get their future goals.

Additionally, it is also objective of the research to determine the cost of training keeping in view the financial limitation of the banks. Training is very important factor inside the organization but distribution of financial resources effectively and efficiently is very important.

The general object of this research is to compare cost and benefit of training which helps managers to make effective decisions.

\section{Literature Review}

Training cost is very important to consider as it can be possible that cost increase than benefits. The human resources management has to calculate the cost and measure the benefits and finally compare cost and benefit for analysis. Training includes both direct and indirect cost which includes arrangement of training, fees 
of trainer, material cost, participant's salaries, administrative record keeping, cataloging, shipping etc. These variables of cost are important to calculate as one can exactly determine the worth of training and compare it to cost incurred. "Theorems for defining, measuring, and engineering human performance are considered seminal in the HRD field. (Gilbert's 1978 p.3)

Two factors cost and benefits are interrelated to each other. Human Resource Managers must consider the both factors carefully and measure the impact level accordingly. According to Natalie S. Glance "on one side employees contribution to the organization comes in outcome of training and on the other hand workers production on the higher rates may affect the organization" (Natalie, 1997)

The emphasis on HRD financial analysis has been highlighted by many authors. "HRD professionals reluctant to account for training need to reorient their thinking to face today's business realities" (Carnevale and Schulz 1990,p. 2).

The manager and other key personnel responsible for conducting training must be carefully examine the worth of the training and measure the results accordingly. Most of human resources professional have developed mathematical formulas to consider the cost as well as benefits of the training like Training cost Analysis (Head, 1985).

Some managers think that training is total wastage of time because it helps little to increase the overall performance of the individuals of the organizations. However, some managers are still of view that training is most important factor which create a sense to increase human capabilities and do more in human development. "it is very exiting... it is very expensive. It is also vastly time and resources consuming. What makes it bearable, however, is comforting thought that we are doing the right thing for our people. We are investing in our most important assets" (Harold, October 1998 p.1)

The increasing emphasis on the training results from the increasing strategies from the competitors, new product lines, quick and unpredictable changes in the environment, increasing concentration on high quality goods. In other words it can be said these are driving forces for the conduction of training in different organizations. "Rapid and unpredictable changes in their operating environments are requiring organizations to have adaptable and competent employees, more so than previously. The increased emphasis on high quality goods and services, in the face of greater competition in the marketplace, is making it more necessary than ever for organizations to equip their employees with the relevant skills and develop their appropriate competencies." (Christopher Orpen March 1999 p.2).

The main factor here is to determine the return on investment which company incurred on the training sessions. Return on investment (ROI) in human resource development (HRD) has been a hot issue pursued by many HRD researchers, practitioners, and organizations during the past decade (Phillips, 1997 p.3).

One aspect of training is that it increases not only the performance of employees inside the organization but it also adds workers performance and, thus, increase the increases the capability of employees at economic level. This can increase the Gross Production level in the country and help to achieve economic prosperity. 
"A general conclusion of such studies is that training improves labor quality, which in turn counts as one of the most important factors contributing to economic growth" (Sturm, 1993 p. 6).

\section{Research Design}

The research is exploratory and qualitative in nature. The researcher has used questionnaire and conducted interviews from the respondents in order to measure the outcomes of training conducted in bank. The researcher has also gone through secondary data for the purpose of accurate and valid measurement.

\subsection{Sampling Method and Data Collection Techniques}

The data is collected from the employees of United Bank Limited (UBL) Clifton, Karachi. The total population of employees working in different branches of bank in Clifton area is 500. The researcher is taken sample of $25 \%$ for best and accurate representation of whole population. Data is collected through convenience sampling method. The bank which were included in the survey are UBL KHAYYABAN-E-SHAMSHIR, UBL GIZRI, UBL SUNSET BOULEVARD DHS, UBL DEFENCE HOUSING SOCIETY, UBL DEFENCE GARDEN, UBL KEHKASHAN CLIFTON and UBL SEAVIEW DHA CLIFTON

\subsection{Data Analysis Techniques}

The descriptive statistical tools are used for analysis of data. For the analysis and presentation of graphs, researcher has got help from software SPSS and MS Excel.

\section{Data Analysis and Findings}

The questionnaires were distributed among the employees of United Bank Limited as they can submit their views regarding the subject matter. Three different questionnaires were made. The first questionnaire was distributed among employees of UBL bank to measure the level of benefit of training. The second questionnaire is distributed among top level manager, training designer and personnel from finance department. Finally, the third type of questionnaire is distribution among customers who avail the services of the United Bank Limited for the purpose of effective measurement. As customers receive services of the bank, they can effectively evaluate the outcome and submit their responses accordingly. 


\subsection{Measurement of Benefit of Training}

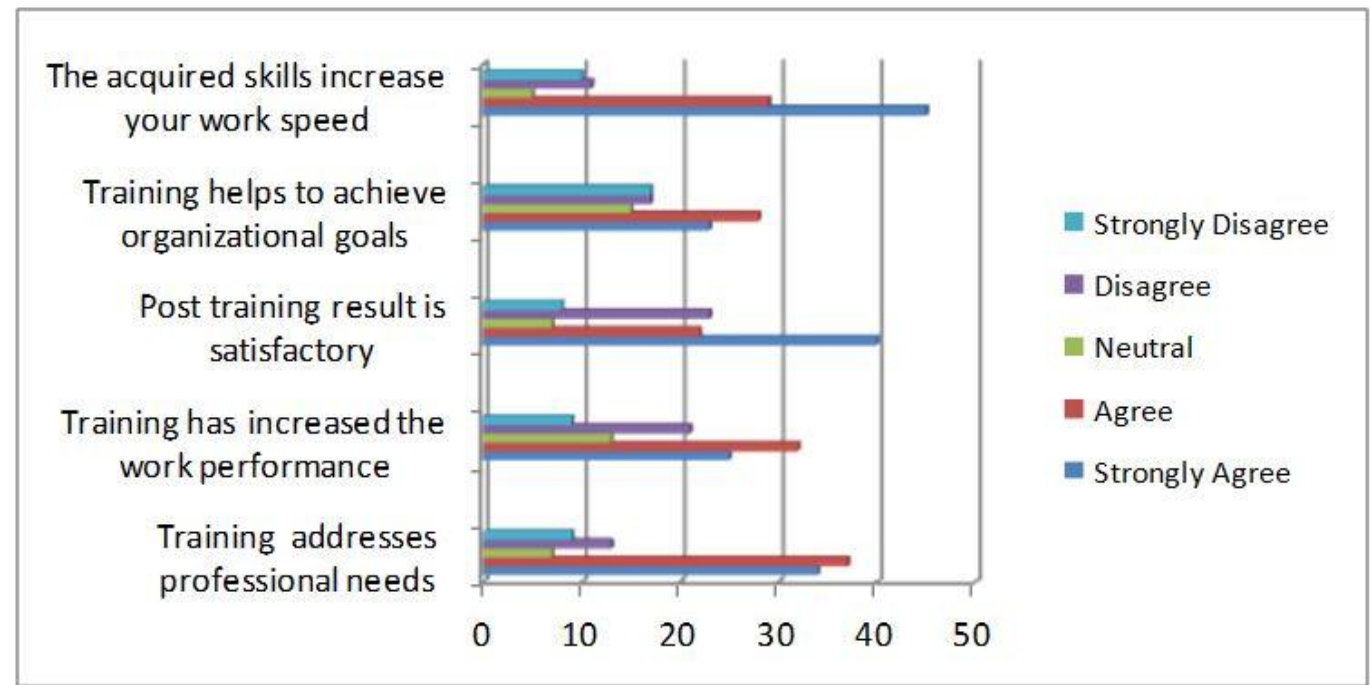

Fig 1: Benefit of Training

The graph clearly shows that employees are very much satisfied with the training as they have gained necessary skills, knowledge and competency. Majority as 71 of employees said that training addresses their professional needs. However, 22 percent of employees are still not satisfied with benefits of training as they were of view that training has increased benefits but cost is much higher than benefits. Approximately $57 \%$ of employees said that they have improved their performance after training while $30 \%$ of employees were against the statement that they have improved their performance. In the same connection, $62 \%$ of employees responded that they are satisfied with the result of training but still $31 \%$ of employees showed their dissatisfaction from the training. Talking about the organizational goals, $51 \%$ of employees said that training helps in achieving organizational goals while $34 \%$ of employees went against the statement. Majority as $74 \%$ of employees said that acquired skilled from training has increased their work speed and reliable work. $21 \%$ of employees said that they have same work speed as they had earlier. 


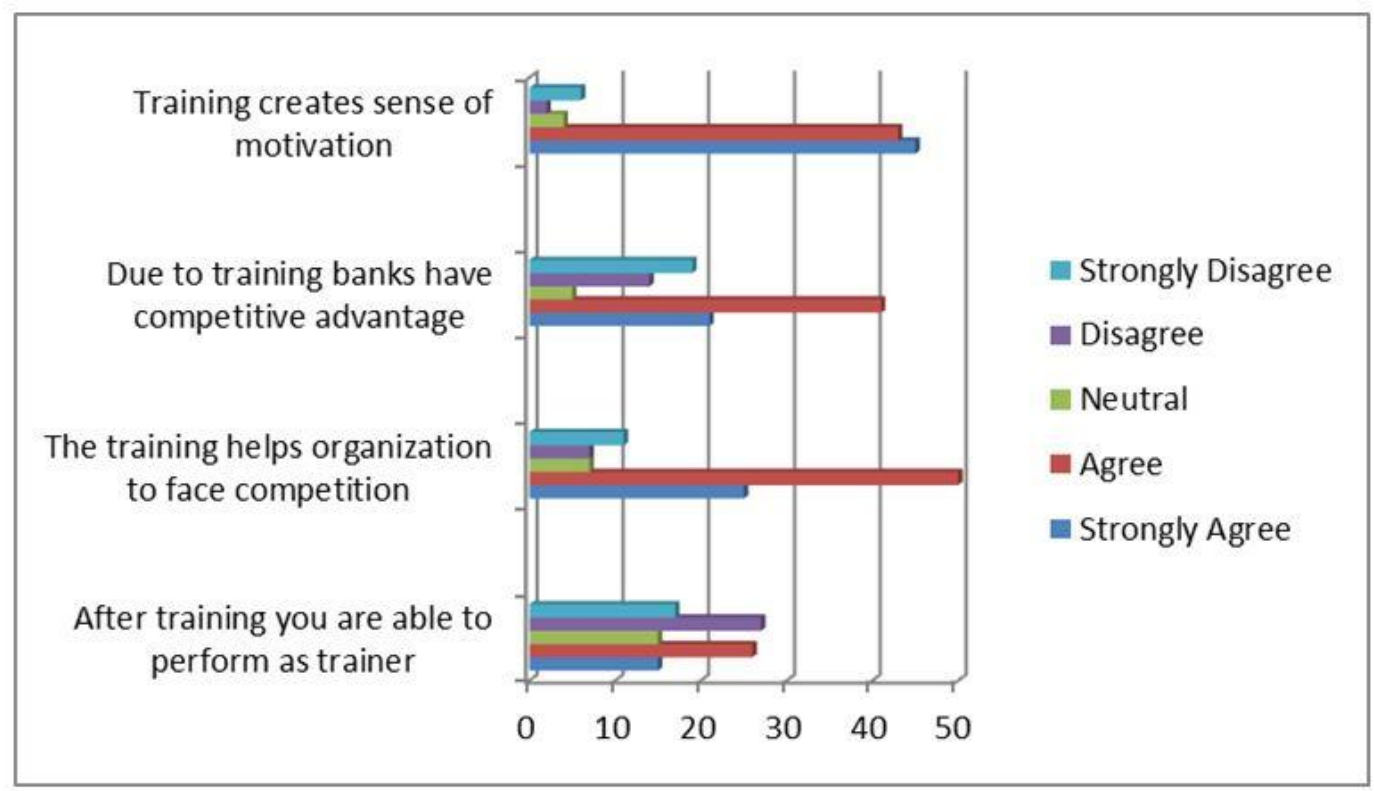

Fig 2: Benefit of Training

The figure-2 also shows the level of benefits extracted from the training. Approximately $41 \%$ of employees said that they can perform their services as trainer after getting intensive training. While dissatisfaction ratio remain high as $44 \%$ of employees said that it is little bit difficult to perform as trainer. Responding to question whether training helps the organization to face the competition, majority as $75 \%$ of employees said that training increases skills of employees and thus helps organization to face the competition in job market. However, $18 \%$ were disagreeing with the statement that training helps organizations to face the competition. The researcher has received almost same level of response from the employees when asked training has created competitive advantage for the organization as almost $62 \%$ of employees went in favor of the statement. However, $33 \%$ of employees said that training has not created a competitive advantage for the organization. Training is also helpful to achieve organizational goals as $51 \%$ of employees said that training is best source to do so. While $34 \%$ of employees said that training is not so much helpful in achieving organization goals. Talking about speed in work performance, the majority as $74 \%$ of employees said that they have boost up their speed and produce effective, timely and reliable work. But still $21 \%$ of employees said that they have same level of speed of work which they have earlier.

\subsection{Measurement of Cost of Training}

Certain questions were asked from the respondents about cost of trainers. The responding were including top level managers, training designers, finance department and other personnel who are involved in designing of training. Talking 
about time, $70 \%$ of respondents said that training is expensive in terms of time cost. Only $11 \%$ of respondents said that training is not costly in terms of time when compared to benefits. Approximately $65 \%$ of respondent went against the statement that training requires lot of paper work. While $32 \%$ of responding said that training is costly in terms of paper work and required huge cost of incur. Training is costly in terms of purchasing and installation of hardware. 56\% of employees said that training is costly because it requires lot of hardware purchase and install. However, $36 \%$ of respondents said that training is not so expensive in that sense. Talking about the fees of professional trainers, majority as $65 \%$ of respondents said that trainers are very expensive to hire. However, $28 \%$ of respondents said that trainers are also available at reason fees which can be affordable by organization.

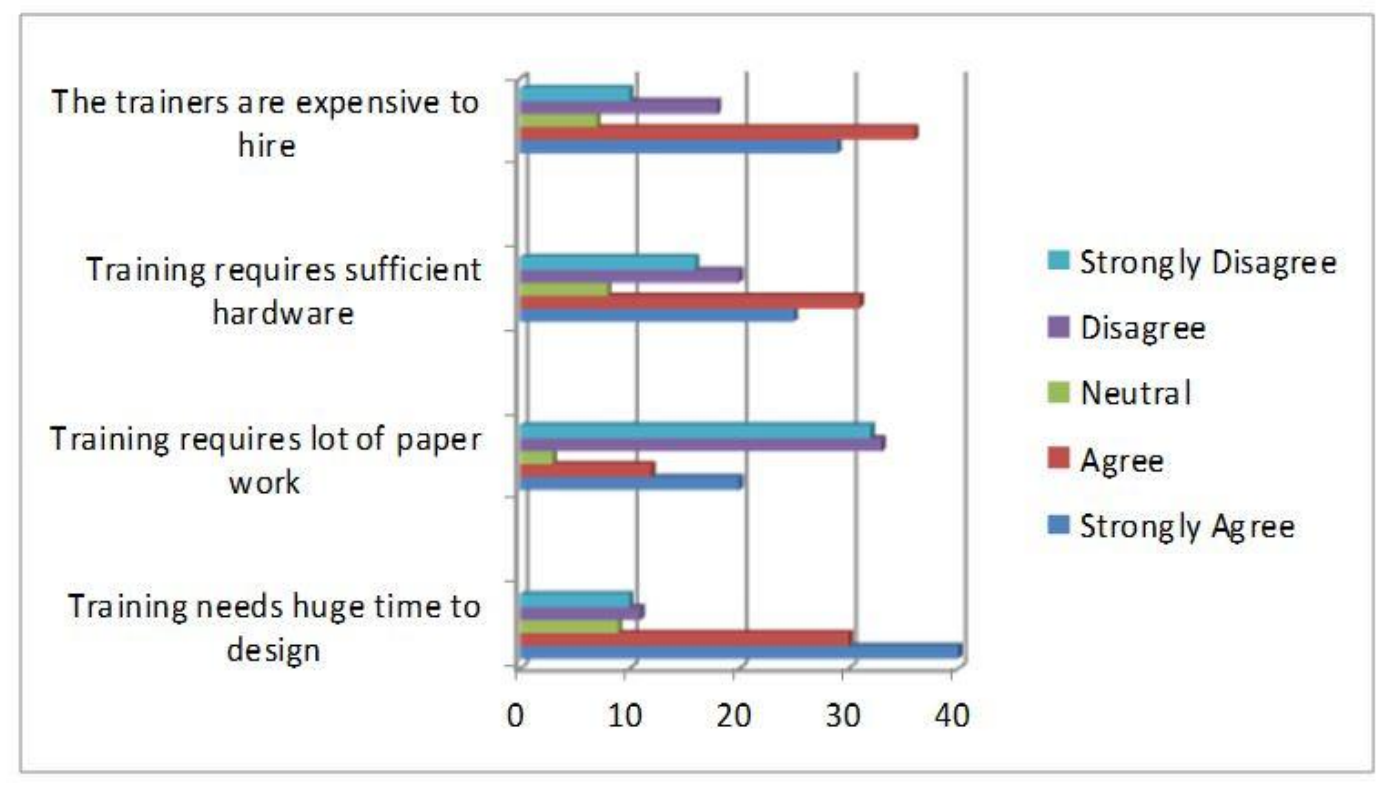

Fig 3: Cost of Training

\subsection{Measurement of Customer Satisfaction}

This portion shows the response of customers who avail the services of UBL bank at Clifton Karachi. The figure shows complete satisfaction of customers regarding services of bank after training. 54\% of respondents said that bank staff is qualified in handling transactions while $24 \%$ of employees said that still there is need for improvement. Majority as $92 \%$ of employees said that bank is facilitating its customers after training. However, very thin ratio of customer as $6 \%$ said that system need some more steps to provide complete facility to customers. Most of customers were of view that work of function is much more reliable than ever before. Almost $81 \%$ said that work is reliable while $11 \%$ of employees show their dissatisfaction about the reliability. Majority as 49 of employees said that they are 
receiving fast service when compare to previous service. However, $29 \%$ of customers said that level of service is same as it was before the training. Talking about the over satisfaction level of customers, $68 \%$ of employees showed their satisfaction on current service and work performance of bank. However, 26 of employees said that bank's service is not satisfactory.

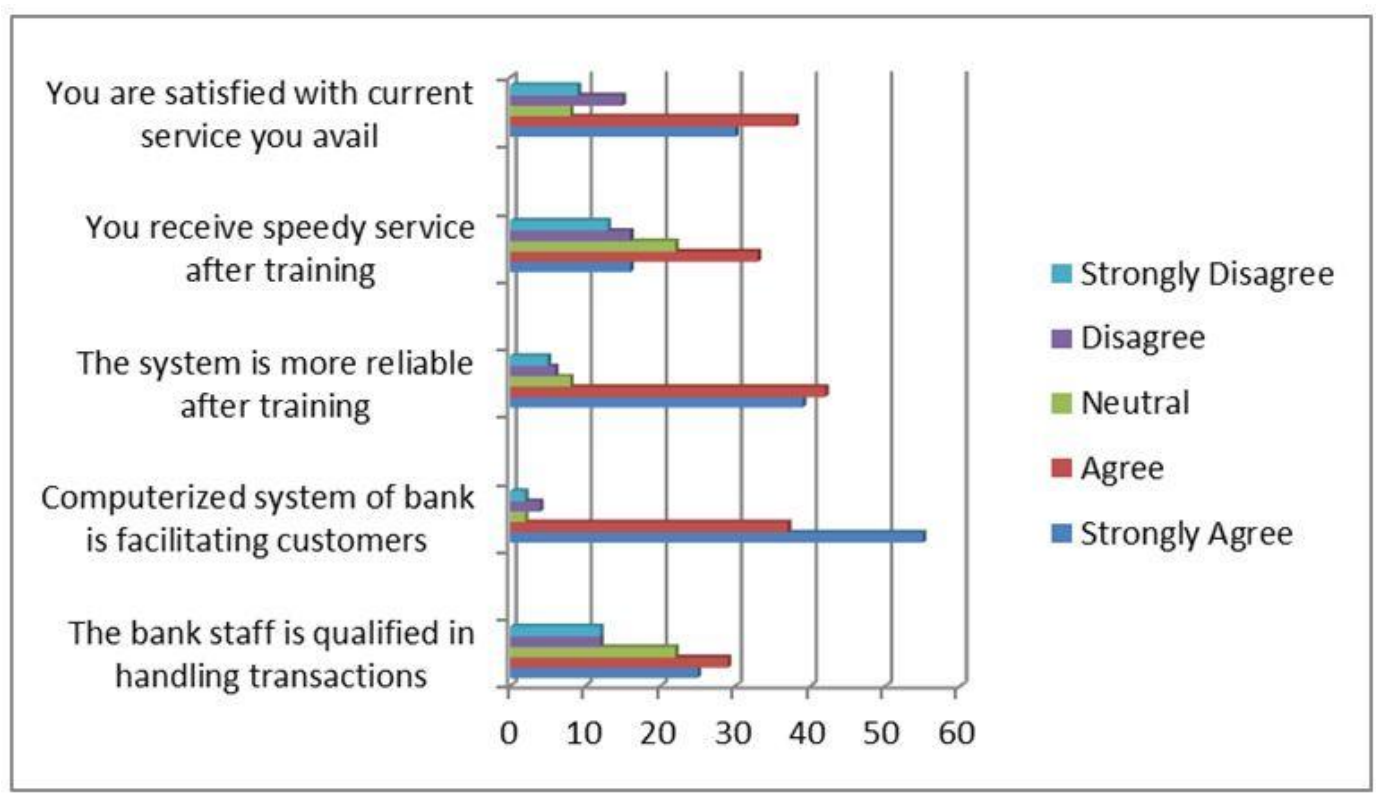

Fig 4: Customer Satisfaction

\section{Conclusion}

The analysis completely shows that organization has gained the efficiency more than the cost. This was main challenge for the bank to switch over from manual work to computerize with expansion of transactions in banking sector. Before going through intensive training, bank went through cost benefit analysis and result found that cost would be high as management was not in position to predict the skills which would be acquired by the staff. It was found through interviews with top level managers that need of training made us confuse as it required huge cost to undergo. The second aspect was to make ready the whole staff throughout the country in different branches for accepting and adopting new change in the sector.

Employees motivation is also enhanced as they have gained new skills which make them survive in modern edge of job market. Work is performed with speed and reliability. However, some technical faults may occur at sometimes but staff considers its affect less when they compare it with the facilities acquired and made the transaction smooth and reliable for customers. Staff is also of view that sometimes customers are not in position to perform their obligations while 
making transaction as they don't exactly know what changes have been made so for. At many branches management has installed demand slip machines but some customers are even not familiar how to operate those machines. As transaction is process where both parties customer and banker have to perform their respective obligations therefore both parties must be familiar with the new technologies, procedures and patterns adopted by the management.

The other side of analysis shows that cost incurred is very high but it is less when matched with the benefits in terms of skills, competencies and knowledge acquired. The cost of hardware, cost of trainer, personnel cost, error checking time, rework, scriptwriting etc. are factors need extra time and financial resources to manage. Manager are of view that cost is not only measured in the terms of currency but it is also in the shape of energy, psychological cost, time etc. when training become successful we feel that we have received our output but in case of failure we have to be careful while re-arranging the whole resources. This is very difficult task that we have again to combine the resources and go through detecting the errors and make it sustainable.

Most managers are of view that major cost to change the system was high and it incurred once. However, we are getting outcomes quick, reliable and satisfying our customer that is long lasting. If one system work for long time period that is most important for the management despite that cost is high to incur.

With this new computerized system bank has also expanded the transactions like remittance, on line pay draft, etc. These transactions are also source of revenue for the bank. So it can be said that bank has gained efficiency rather than cost.

\section{Acknowledgement}

My first and foremost thanks are due to my respected colleagues Dr. Aftab Ahmed Shaikh and Ghulam Ali Mashori who provided every assistance and guidance during this research work. They provided their valuable suggestions during the preparation of this research paper.

I would also convey thanks to employees of UBL Karachi, who provided their great support and helped me to accomplish this task.

Finally, many thanks go to my colleagues and friends who gave their inputs and improved the quality of this research work.

\section{References}

[1] Camevale. A, \& Schulz, E. (1990). Economic accountability for training: Demand and responses. Training and Development Journal, Supplement, 44 (7), S2-54.

[2] Christopher Orpen (1999), "The Influence of Training Environment on Training Motivation and Perceived Training Quality", International Journal of Training and Development, Blackwell Publishers, USA. 
[3] Gilbert, T. F (1978), “ Human competence: Engineering worthy performance". New York: McGraw-Hill.

[4] Greg G. Wang, Zhengxia Dou (2002), "A System Approach to Measuring Return on Investment for HRD Intervensions", Human Resource Development Quarterly, vol 13, no 2 Wiley Publishers Inc.

[5] Harold D., (2007), "Calculating Return on Investment in Training: A Critical Analysis and Case Study", Journal of Performance Improvement, vol 37, issue 8, pages 9-20, Wiley Publications.

[6] Head, G. E. (1985). Training cost analysis. Washington, DC: Marlin Press.

[7] Natalie S. Glance, (1997), "Training and Turnover in Evolution of organizations", A journal of the Institute for Operations Research and the Management Sciences, vol 8, no 1. Organization Sciences Publications.

[8] Phillips J. (1997). "Handbook of training evaluation and measurement methods". (3rd ed.). Houston: Gulf. 